\title{
Optimization of Tooth Root Profile Using Bezier Curve with G2 Continuity to Reduce Bending Stress of Asymmetric Spur Gear Tooth
}

\author{
Priyakant Vaghela ${ }^{1, a}$ and Jagdish Prajapati ${ }^{2}$ \\ ${ }^{1}$ Mechanical Engineering Department, R C Technical Institute, Gujarat Technological University, Gujarat, India \\ ${ }^{2}$ Faculty of technology and Engineering, The Maharaja Sayajirao University of Baroda, Vadodara, Gujarat, India
}

\begin{abstract}
This research describes simple and innovative approach to reduce bending stress at tooth root of asymmetric spur gear tooth which is desire for improve high load carrying capacity. In gear design at root of tooth circular-filleted is widely used. Blending of the involute profile of tooth and circular fillet creates discontinuity at root of tooth causes stress concentration occurs. In order to minimize stress concentration, geometric continuity of order 2 at the blending of gear tooth plays very important role. Bezier curve is used with geometric continuity of order 2 at tooth root of asymmetric spur gear to reduce bending stress.
\end{abstract}

\section{Introduction}

Gears are very important part in all of machinery used in current times. Gear design is an extremely difficult art. High load-carrying capacity, less expensive, quieter running, lighter weight, and longer life are the primary aim of present industry for making gears. Current focus of gear design in industry is on failure occurs at critical section/root of tooth. One major cause of gear failure is fracture at root of the gear tooth due to bending fatigue [1]. The bending strength is influenced by: load location at HPSTC, load value, number teeth on the gear, fillet radius at root of tooth etc.

Failure at root of tooth can be reduced by optimizing geometrical shape of standard symmetric gear tooth [1-2]. In order to achieve this goal, pressure angle on drive side profile (as compare to coast side) can be increases within constraint [3-4]. Due to different pressure angle on both sides of gear tooth gear becomes asymmetric gear. In asymmetric spur gear bending stress at tooth root is reduced as compare to standard symmetric spur gear [5-6].

For further reduction in bending stress, it is necessary to optimize root profile of asymmetric spur gear tooth. Blending of the involute profile of tooth and circular fillet creates discontinuity at root of tooth causes stress concentration occurs [7-8]. In order to minimize stress concentration, geometric continuity of order 2 at the blending of gear tooth plays very important role [9-10]. In this paper a bezier curve is used with geometric continuity of order 2 at tooth root to reduce bending stress of asymmetric spur gear tooth.

\section{Mathematical model of gear tooth}

\footnotetext{
${ }^{\mathrm{a}}$ Corresponding author : pavaghela@yahoo.co.in
} 
Drive side pressure angle increases, base circle radius for drive side decreases compare to coast side. Hence long involute profile is available on drive side from tip (point A) to base circle radius (point C).

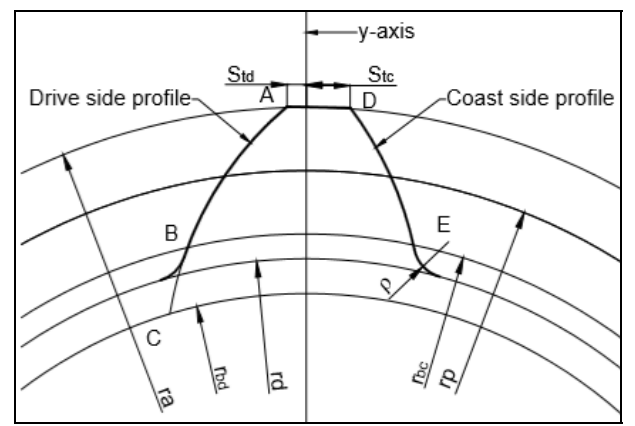

Figure 1. Asymmetric involute spur gear tooth

Whereas on coast side available profile is from tip (point D) to base circle radius (point E) as shown in figure 1.

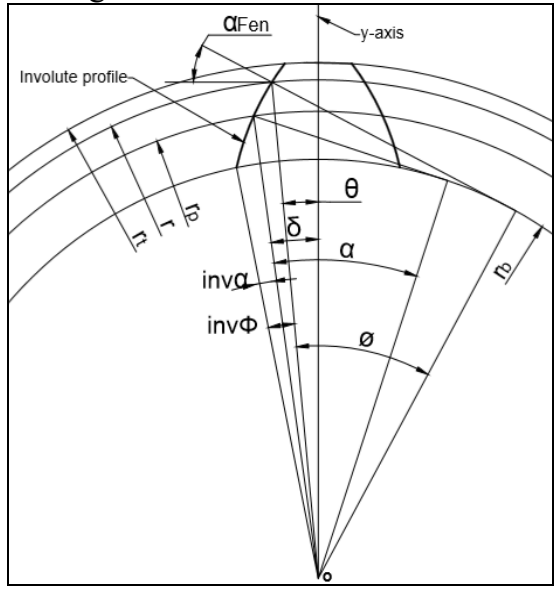

Figure 2(a). Representation of angle $\theta$

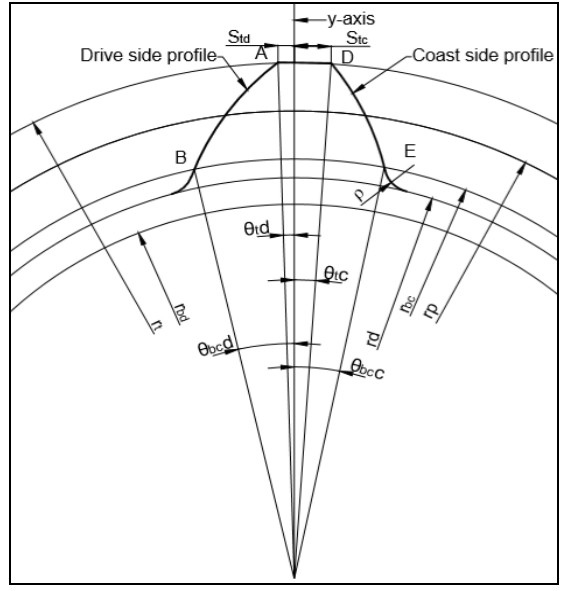

Figure 2(b). Mathematical representation of involute $\mathrm{profile} / \mathrm{gear}$ tooth

Consider centre of gear as origin and vertical line passes through origin is a y axis. As shown in figure 2(a), $\theta$ is an angle at radius $\mathrm{r}$ w.r.t $\mathrm{y}$-axis. Angle $\theta$ is a variable, which is required to develop involute profile of asymmetric spur gear tooth. Angle $\theta$ and radius $r$ define location of points on the involute profile which is given by:

$$
\theta=\frac{\pi}{2 \cdot z}+\tan \alpha-\alpha-\left(\tan \left(\cos ^{-1}\left(\frac{r_{p}}{r} \cdot \cos \alpha\right)\right)-\left(\cos ^{-1}\left(\frac{r_{p}}{r} \cdot \cos \alpha\right)\right)\right)
$$

To develop drive and coast side profile, $\theta$ is varied between $\theta_{b c} d \leq \theta \leq \theta_{t} d$ and $\theta_{b c} c \leq \theta \leq \theta_{t} c$ respectively as shown in figure $2(\mathrm{~b})$.

Involute profile coordinate $\left(x_{i}, y_{i}\right)$ of an arbitrary point $i$ for drive and coast side given by:

$$
\begin{aligned}
x_{i} & =r_{i} \cdot \cos \theta_{i} \\
y_{i} & =r_{i} \cdot \sin \theta_{i} \\
\theta_{i}= & \left.\frac{\pi}{2 . z}+\tan \alpha-\alpha-\left(\tan \left(\cos ^{-1}\left(\frac{r_{p}}{r_{i}} \cdot \cos \alpha\right)\right)-\left(\cos ^{-1}\left(\frac{r_{p}}{r_{i}} \cdot \cos \alpha\right)\right)\right)\right)
\end{aligned}
$$


Where design parameter $\theta_{i}$ is varied

$\theta_{b c} d \leq \theta_{i} \leq \theta_{t} d$ and $\alpha=\alpha_{d}$ for drive side profile

$-\theta_{b c} c \leq \theta_{i} \leq-\theta_{t} c$ and $\alpha=\alpha_{c}$ for coast side profile

\section{Optimization of tooth root profile}

\subsection{G2 Continuity}

G2 continuity means geometric continuity of order 2 . It represents position of end point, equal tangent and equal curvature continuity between two geometric curves [10]. It is necessary to reduce stress concentration at tooth root to reduce bending stress.

\subsection{Bezier curve}

Bezier curve mimics the shape of its control polygon and always passes through its ends points [11]. Bezier curve is defined by

$$
\begin{gathered}
P(t)=\sum_{i=0}^{n} B_{i} J_{n, i}(t) \quad 0 \leq t \leq 1 \\
J_{n, i}(t)=\left(\begin{array}{c}
n \\
i
\end{array}\right) \cdot t^{i}(1-t)^{n-i} \quad\left(\begin{array}{c}
n \\
i
\end{array}\right)=\frac{n !}{i !(n-1) !}
\end{gathered}
$$

\subsection{Optimize Bezier curve fillet with G2 continuity at the blending /critical section}

In gear design at root of tooth circular-filleted is used [12] as shown in figure 3(a). Due to this at root, stress concentration occurs. To reduce stress concentration at the common end point of involute tooth profile and circular fillet, Bezier curve (at root of tooth) with G2 continuity has been developed as shown in figure $3(\mathrm{~b})$.

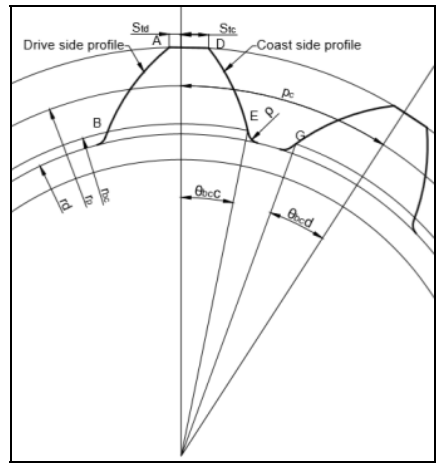

Figure 3(a). Circular fillet at gear tooth root

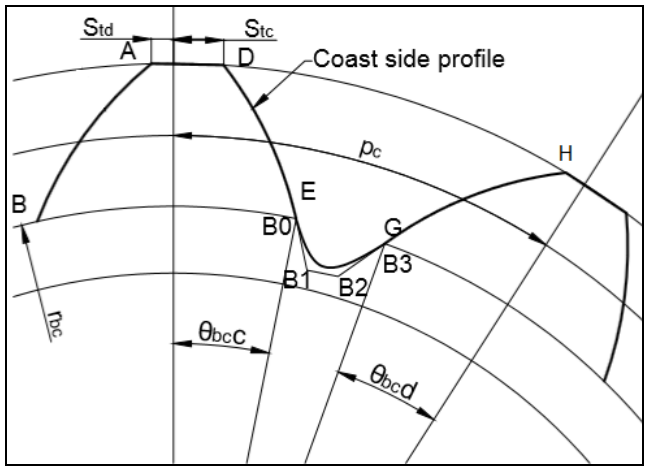

Figure 3(b). Developed fillet at tooth root with G2 continuity

If the radius of curvature is same at common end point, curves are known as curvature continuous. Tangent and curvature continuous is possible only when both first and second derivations of the quations are equal at common end point [10-11]. First and second derivations of bezier curve at end points are [11].

$$
P^{\prime}(0)=n\left(B_{1}-B_{0}\right)
$$




$$
\begin{aligned}
& P^{\prime}(1)=n\left(B_{n}-B_{n-1}\right) \\
& P^{\prime \prime}(0)=n(n-1)\left(B_{0}-2 B_{1}+B_{2}\right) \\
& P^{\prime \prime}(1)=n(n-1)\left(B_{n}-2 B_{n-1}+B_{n-2}\right)
\end{aligned}
$$

First and second order derivative of the curve $\mathrm{DE}$ and $\mathrm{GH}$ at end points gives value of $\mathrm{P}^{\prime}(0), \mathrm{P}^{\prime \prime}(0)$, $\mathrm{P}^{\prime}(1)$ and $\mathrm{P}^{\prime \prime}(1)$ respectively. $\mathrm{B}_{0}$ and $\mathrm{B}_{3}$ are end points of curve DE and GH respectively. $\mathrm{B}_{0}$ and $\mathrm{B}_{3}$ are known points. Based on equation 4 to 7 a code has been developed to obtain required points B1 and $\mathrm{B} 2$ at root of tooth.

\section{Geometric model of asymmetric spur gear tooth}

Following parameters and material used for geometric model and analysis. It is presented in table $1 \&$ 2 [13].

Table 1. Design parameters [13]

\begin{tabular}{|c|c|c|}
\hline Design Parameters & Value & Unit \\
\hline Pressure angle, Drive / Coast side & $38^{0} / 20^{\circ}$ & Degree \\
\hline Total tooth on pinion and gear & 25 and 25 & - \\
\hline Module & 4 & $\mathrm{~mm}$ \\
\hline Power & 18 & $\mathrm{KW}$ \\
\hline Rotation & 1600 & $\mathrm{RPM}$ \\
\hline
\end{tabular}

Table 2. Material- (Used for ANSYS Simulation)

\begin{tabular}{|c|c|c|}
\hline Parameters & Value & Unit \\
\hline Young Modulus & $2 \times 10^{11}$ & $\mathrm{~N} / \mathrm{m}^{2}$ \\
\hline Poisson ratio & 0.266 & - \\
\hline Density & 7860 & $\mathrm{Kg} / \mathrm{m}^{3}$ \\
\hline Yield strength & $2.5 \times 10^{8}$ & $\mathrm{~N} / \mathrm{m}^{2}$ \\
\hline
\end{tabular}

As per above parameter and developed mathematical model, involute profile of asymmetric spur gear tooth is generated shown in figure 4(a) and (b). 


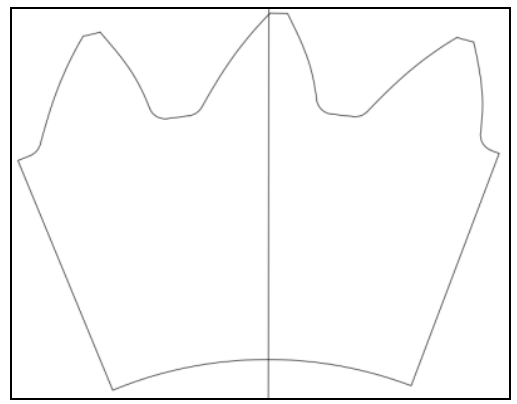

Figure 4(a). Asymmetric involute spur gear $\left(\alpha_{d}=38^{0}\right.$, $\left.\alpha_{c}=20^{\circ}\right)$ with normal fillet $(\rho=1.2 \mathrm{~mm})$ at root of tooth

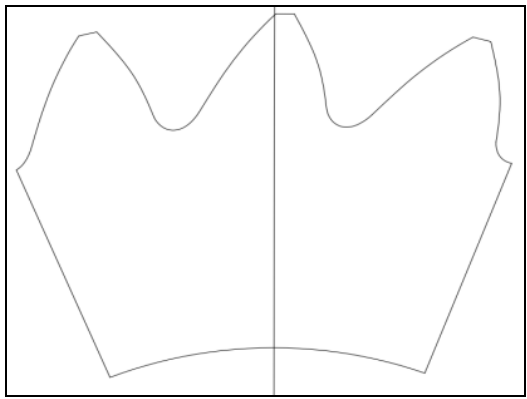

Figure 4(b). Asymmetric involute spur gear $\left(\alpha_{\mathrm{d}}=38^{0}\right.$, $\left.\alpha_{\mathrm{c}}=20^{0}\right)$ with $\mathrm{G} 2$ continuity at root of tooth

\section{Analysis of tooth in ANSYS software}

Finite element analyses have been carried out for developed tooth shown in fig. 5(a) and (b). In this simulation tooth is considered as cantilever beam and loaded on drive side. The material used for simulation is presented in table 2. For analysis, following assumptions are made: 1) There is no misalignment in gear transmission, 2) Load is static, 3) Load is uniformly distributed and 4) Gear tooth material is homogenous.

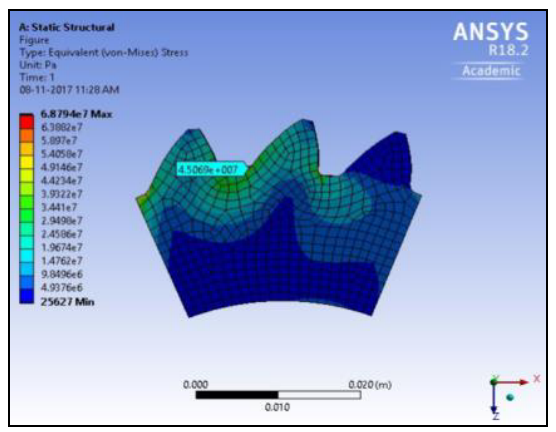

Figure 5(a). ANSYS result for asymmetric involute spur gear $\left(\alpha_{\mathrm{d}}=38^{0}, \alpha_{\mathrm{c}}=20^{0}\right)$ with normal fillet $(\rho=1.2$ $\mathrm{mm})$ at root of tooth

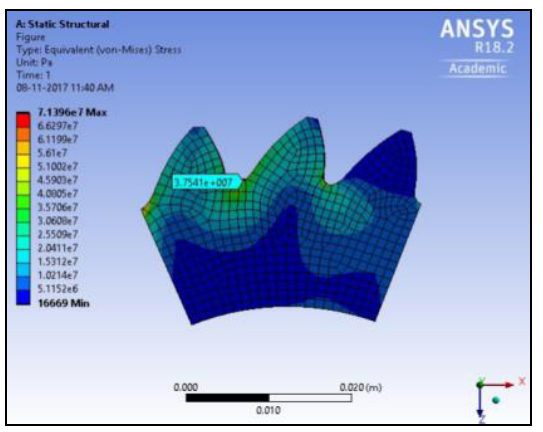

Figure 5(b). Asymmetric involute spur gear $\left(\alpha_{\mathrm{d}}=38^{0}\right.$, $\alpha_{c}=20^{\circ}$ ) with $\mathrm{G} 2$ continuity at root of tooth.

\section{Results}

Comparison has been made between normal fillet asymmetric spur gear tooth with modified gear tooth. FEA simulation show that Von mises stress at root of symmetric gear $\left(\alpha_{d}=38^{0}\right.$ and $\left.\alpha_{c}=20^{\circ}\right)$ with normal fillet is $45.06 \mathrm{Mpa}$. Von mises stress at root of tooth of asymmetric gear $\left(\alpha_{\mathrm{d}}=38^{0}\right.$ and $\alpha_{\mathrm{c}}$ $=20^{\circ}$ ) with $\mathrm{G} 2$ continuity is $37.54 \mathrm{Mpa}$. Von mises stress is reduced by $16.68 \%$ compared with normal fillet asymmetric spur gear. A result has been presented in table 3 .

Table 3. Result table

\begin{tabular}{|l|c|c|}
\hline \multicolumn{1}{|c|}{ Parameters } & Value & Unit \\
\hline $\begin{array}{l}\text { Bending stress (asymmetric gear } / 20^{0}-38^{0} \text { ) with normal } \\
\text { fillet radius }\end{array}$ & 45.06 & Mpa \\
\hline $\begin{array}{l}\text { Bending stress (asymmetric gear } / 20^{0}-38^{0} \text { ) with G2 } \\
\text { continuity }\end{array}$ & 37.54 & Mpa \\
\hline
\end{tabular}




\section{Conclusions}

Root profile is optimized to reduce bending stress of asymmetric involute spur gear tooth. Von mises stress of optimized root profile is analyzed and compared with normal fillet profile of asymmetric gear. Von mises stress is reduced by $16.68 \%$ by optimization of root profile. Stress concentration of modified asymmetric spur gear has been significantly reduced.

\section{References}

1. Dudley Darle, Handbook of Practical Gear Design, (Ist Edition, CRC Press London,(2009)

2. A. Kapelevich, "Geometry and design of involute spur gears with asymmetric teeth" Mechanism and Machine Theory 35,117-130, (2000)

3. F. Litvin,,Q. Lian, A. Kapelevich, “Asymmetric modified spur gear drives: reduction of noise, localization of contact, simulation of meshing and stress analysis" Computer Methods Applied Mechanics and Engineering. 188,363-390, (2000)

4. Th. Costopoulos, V. Spitas "Reduction of gear fillet stresses by using one-sided involute asymmetric teeth", Mechanism and Machine Theory 44,1524-1534, (2009)

5. N. Pedersen, "Improving bending stress in spur gears using asymmetric gears and Shape optimization" Mechanism and Machine Theory 45,1707-1720, (2010)

6. V. Senthil Kumar, D.Muni, G. Muthuveerappan "Optimization of asymmetric spur gear drives to improve the bending load capacity" Mechanism and Machine Theory 43 ,829-858,(2008)

7. A. Kawalec, J. Wiktor, D. Ceglarek," Comparative Analysis of Tooth-Root Strength Using ISO and AGMA Standards in Spur and Helical Gears With FEM-based Verification”, Journal of Mechanical Design, 128 (2006)

8. V. Spitas, Th. Costopoulos and C. Spitas, "Increasing the Strength of Standard Involute Gear Teeth with Novel Circular Root Fillet Design", American Journal of Applied Sciences 2,6,10581064, (2005)

9. ISO 6336 Standard, Calculation of Load Capacity of Spur and Helical Gears

10. Lizheng Lu, "Optimal multi-degree reduction of Bezier curve with G2 continuty" Computer aided geometric design, 23 ,673-683,(2006)

11. D.Rogers, J. Adams, Mathematical element for computer graphics, (1990)

12. T. Zou , "Optimization of tooth root profile of spur gears for maximum load-carrying capacity", Proceedings of ASME International design engineering technical conference and computers and information in engineering conference, $(2014)$

13. P.Vaghela, Master degree thesis "Effect of rim thickness on asymmetric spur gear tooth bending stress", Gujarat technological university, (2011) 